\title{
Late Jurassic Sunosuchus (Crocodylomorpha, Neosuchia) from the Qigu Formation in the Junggar Basin (Xinjiang, China)
}

\author{
Rico Schellhorn*, ${ }^{*}$, Daniela Schwarz-Wings ${ }^{2}$, Michael W. Maisch ${ }^{1}$ and Oliver Wings ${ }^{1,2}$ \\ 1 Institut für Geowissenschaften, Universität Tübingen, Sigwartstraße 10, 72076 Tübingen, Germany. \\ E-mail: rico.schellhorn@uni-tuebingen.de; maisch@uni-tuebingen.de; oliver.wings@web.de \\ 2 Museum für Naturkunde Berlin, Invalidenstraße 43, 10115 Berlin, Germany. \\ E-mail: d.schwarz-wings@museum.hu-berlin.de
}

Received 29 May 2008

Accepted 15 August 2008

Published 20 February 2009

\section{Key Words}

Archosauria

skull

cervical region

Oxfordian

Liuhuanggou

\begin{abstract}
Various bone fragments of the crocodylomorph Sunosuchus from the Late Jurassic (Oxfordian) Qigu Formation in the southern Junggar Basin (Xinjiang Province/China) can be assigned to a single specimen and comprise the occipital region of the skull, mandibular fragments, and few postcranial elements. The size of the reconstructed skull does not exceed $30 \mathrm{~cm}$ in length and $13 \mathrm{~cm}$ in width. After comparison with other Sunosuchus species, the generic diagnosis of the genus can be expanded with the character of a lobe-like and unsculptured posterolateral process of the squamosal. The specimen is the first evidence of a crocodylomorph from the Qigu Formation and extends the geographical and stratigraphical range of Sunosuchus.
\end{abstract}

\section{Introduction}

The Junggar Basin, located in the Autonomous Region Xinjiang (NW China), is filled with an almost continuous sequence of Mesozoic and Cenozoic sedimentary rocks. The southern part of the basin bears large exposures of Middle and Late Jurassic terrestrial siltstones and sandstones of alluvial and lacustrine origin. Since 1999, this basin is the focus of a Sino-German research project carried out by the Geological Survey of Xinjiang, the Jilin University, and the Institut für Geowissenschaften der Universität Tübingen. In the last years, the Qigu and Toutunhe Formations have produced a large number of fossil vertebrates including hybodontid sharks and actinopterygians (Maisch et al. 2001, 2003a), temnospondyl amphibians (Maisch \& Matzke 2005), xinjiangchelyid turtles (Matzke et al. 2004, 2005), a goniopholidid crocodylomorph (Maisch et al. 2003b), several dinosaur taxa (Dong 1993, 2001; Wings et al. 2007a, 2007b), as well as docodont and haramyoid mammals (Maisch et al. 2004; Pfretzschner et al. 2005).
In 2001, a crocodylomorph was discovered in the Late Jurassic (Oxfordian) Qigu Formation. The incomplete specimen consists of fragmentary bone material. The posterior region of the skull and mandible are preserved as isolated pieces. The similar provenience, morphology and size of the bones allow assignment to the same individual. Some anterior cervical vertebrae and undetermined small bone fragments have been found associated with the cranial remains. The crocodylomorph bones (Figs 1-3) have been found about $100 \mathrm{~m}$ above the Toutunhe-Qigu boundary sensu Maisch et al. (2003a). The locality is situated approximately $15 \mathrm{~km}$ south of Liuhuanggou and about $50 \mathrm{~km}$ southwest of the city of Urumqi. The same beds also yielded remains of a brachyopid temnospondyl (Maisch \& Matzke 2005), postcranial elements of a second crocodylomorph, fragmentary dinosaur bones, and several specimens of an unusually large xinjiangchelyid turtle, which all remain to be described. This paper is dedicated to the description of the crocodylomorph specimen, which is the first crocodylomorph ever found in the Qigu Formation.

* Corresponding author 
Institutional abbreviations. IFG, Institut für Geowissenschaften, Eberhard Karls Universität Tübingen, Germany; NIGP, Nanjing Institute of Geology and Palaeontology, China; SGP, Sino-German Project collection.

\section{Systematic paleontology}

\author{
Superorder Crocodylomorpha Walker, 1970 \\ (sensu Clark 1986)
}

(unranked) Crocodyliformes Hay, 1930 (sensu Clark 1986)

Division Mesoeucrocodylia Whetstone \& Whybrow, 1983 (sensu Benton \& Clark 1988)

Infradivision Neosuchia Benton \& Clark, 1988

Family Goniopholididae Cope, 1875

\section{Sunosuchus Young, 1948}

Type species. Sunosuchus miaoi Young, 1948; holotype is specimen NIGP $n^{\circ} \mathrm{V} 0090$, nearly complete skull with parts of the lower jaws.

Included species. Sunosuchus thailandicus Buffetaut \& Ingavat, 1980; Sunosuchus shartegensis Efimov, 1988; Sunosuchus junggarensis Wu et al., 1996; Sunosuchus shunanensis Fu, Ming \& Peng, 2005.

Holotype locality, unit, and age. Hanchiahukou near Haishihwan, Yungteng, Gansu, China; Hokou Series; Late Jurassic.

Range. Early Jurassic - Early Cretaceous; Thailand, China.

Emended diagnosis. Medium-sized mesoeucrocodylian that differs from all other members of Goniopholididae by the following derived characters: (1) a narrow snout (rostrum more than twice as long as postorbital region), (2) a small cranial table less than $60 \%$ of maximum skull width at supratemporal fenestrae, (3) frontal with a ridge along midline, (4) lobe-like and unsculptured posterolateral process of the squamosal, with thickened and rugose posterior margin, (5) expanded dorsal surface of retroarticular process facing lateroventrallymediodorsally, (6) large pits wider than long on posterior surface of frontal, (7) dentary symphysis elongated and with a short contribution from splenial.

\section{Sunosuchus sp.}

Referred specimens. SGP 2001/35.1, skull fragment with left and right squamosal, parietal, left exoccipital and supraoccipital; SGP 2001/ 35.2, skull fragment with right squamosal, exoccipital and quadrate; SGP 2001/35.3, posterior end of right quadrate, quadratojugal, jugal, and angular; SGP 2001/35.4, left quadrate; SGP 2001/35.5, basioccipital with occipital condyle; SGP 2001/35.6, fragment of exoccipital and basioccipital with roof of foramen magnum; SGP 2001/35.7, right pterygoid process; SGP 2001/35.8, posterior end of right mandible; SGP 2001/35.9, fragment of right angular and splenial; SGP 2001/ 35.10 , dentary fragment; SGP 2001/35.11, intercentrum of atlas with odontoid process; SGP 2001/35.12, neural spine of axis; SGP 2001/ 35.13 , centrum of axis; SGP 2001/35.14, rib fragment; SGP 2001/ 35.15 , osteoderm fragment; SGP 2001/35.16, proximal metacarpal fragment; SGP 2001/35.17, ?ulna fragment.

All the bone material described here is deposited in the Sino-German Project collection, which is currently housed at the Institut für Geowissenschaften, Universität Tübingen, Germany. The collection is property of the People's Republic of China and it will be transferred to a public Chinese collection after the scientific studies are finished. The final repository will be announced in an internationally accessible geoscience journal.

Locality, unit and age. $15 \mathrm{~km} \mathrm{~S}$ of Liuhuanggou, SW of Urumqi, Junggar Basin, Xinjiang Uygur Autonomous Region, People's Republic of China. Qigu Formation, $100 \mathrm{~m}$ above Toutunhe-Qigu boundary; Late Jurassic (Oxfordian)

\section{Description}

SGP 2001/35.1. This skull fragment comprises parts of the left and right squamosal, parietal, left and right exoccipital, supraoccipital, and basioccipital. The dorsal surfaces of the squamosals and parietal are heavily sculptured with circular pits. In dorsal view, the squamosals contact medially the parietal in a rostrocaudally straight, jagged suture. Anteriorly to the right squamoso-parietal suture, a $3 \mathrm{~mm}$ wide part of the posterior margin of the supratemporal fenestra is visible. The parietal is rectangular in outline, being twice as broad as it is long. It is posteroventrally bounded by the supraoccipital. The posterior margin of the squamosal is slightly posterolaterally curved, therefore slightly concave. In occipital view, the left squamosal extends with a large portion ventrally and it is ventrally connected to the left exoccipital by a suture extending straight from lateroventral to mediodorsal. The medialmost extent of the occipital part of the left squamosal (Fig. 1A, B) contacts the supraoccipital. In occipital view, the supraoccipital is preserved with its dorsal part bearing two well developed supraoccipital processes, which are nearly $5 \mathrm{~mm}$ wide and $4 \mathrm{~mm}$ tall. Medially to the supraoccipital processes lies a bowl-shaped, circular depression, divided by a distinct median ridge. The supraoccipital processes are visible in dorsal view. The supraoccipital is approximately as wide as the parietal. The preserved part of the left exoccipital process underlies the left squamosal and medially contacts the supraoccipital; however, the suture between the latter two bones is not preserved. The exoccipital process is a wing-like structure that is slightly rugose in its lateral and lateroventral parts.

SGP 2001/35.2. The posterolateral half of the right squamosal, most of the right exoccipital and a portion of the right quadrate are preserved in a separate bone fragment (Fig. 1C, D). The posterolateral edge of the right squamosal forms a broad posterolaterally directed process that is unsculptured and tongue-like. The posterolateral margin is convex, thickened, and slightly rugose. In dorsal view, the squamosal is sculptured, except the posteriormost part. In posterior view, the suture to the ventrally adjacent right exoccipital is clearly visible as a straight line. The medial boundary of the right exoccipital is dorsoventrally straight and bounds the supraoccipital dorsally and the basioccipital ventrally. The completely preserved paroccipital process of the exoccipital forms a posterolaterally curved wing ending laterally with a convex, broad margin. The posterior surface of the paroccipital process is medially slightly rugose. The ventral third of the exoccipital is, 
by a distinct horizontally directed step, displaced rostrally. It bears medially a round foramen for the IXXIth cranial nerves (= foramen vagi). Another foramen, presumably for the XIIth cranial nerve, is positioned near the medial margin of the exoccipital and therefore distinctly medially displaced from the foramen vagi. The exoccipital is ventrally supported by the quadrate, which continues at the preserved bone anteriorly. The suture between the exoccipital and the quadrate is visible on the occiput as a simple suture extending in medioventral-laterodorsal direction. In ventral view, the quadrate exposes two crests (sensu Iordansky 1973): crest $\mathrm{A}$ is a weak and anteromedially-posterolaterally directed ridge that ends laterally to crest $\mathrm{B}$. Crest $\mathrm{B}$ is a very high and sharp crest that extends parallel to the long axis of the quadrate; it is accompanied posteriorly by a deep and internally rugose, oval fossa. Another, but very shallow fossa is present between crest A and crest B.

SGP 2001/35.3. This skull fragment bears the remainder of the right quadrate (the rest of which is preserved in SGP 2001/35.2), most of the right quadratojugal and a part of the right jugal (Fig. 1E). A posterior part of the right mandible is agglutinated to the medial surface of the quadratojugal and jugal. The orientation of the right quadrate is posterolateral and ventral. The quadrate articular surface is posteroventrally oriented and divided into a medial and a lateral hemicondyle. Both hemicondyles are separated by a narrow and shallow groove. The long axes of both hemicondyli are oriented with an acute angle of approximately $50^{\circ}$ to each other. The medial hemicondyle is only one-third of the width of the lateral hemicondyle and with its long-axis extends in ventromedial-laterodorsal direction. In posterior view, the lateral hemicondyle is as long as the medial hemicondyle, but significantly broader, and extends in a near-horizontal plane posteromedially to anterolaterally placed. The dorsal quadrate surface is dorsally arched and divided by a longitudinal medial ridge into a dorsomedial and a dorsolateral half. Posteriorly, the medial ridge ends at the medial tip of the medial hemicondyle. The dorsomedial half of the quadrate bears anteriorly a rugosity that represents the articular surface with the overlying exoccipital. In ventral view, the quadrate is concave and anteriorly exhibits the posterior half of the deep fossa paralleling the quadrate crest B. The quadratojugal is anteroposteriorly oriented and wedged between the dorsal quadrate and the ventrally following jugal. The dorsal contact with the quadrate is a serrated suture, whereas the ventral contact suture to the jugal is unserrated. The posterior end of the quadratojugal is a narrow and unsculptured rounding. The dorsolateral surface of the quadratojugal is heavily sculptured, except the anterodorsal fifth adjacent to the quadrate, which is smooth. The jugal extends posteriorly up to the posterior end of the quadratojugal. Its surface is heavily sculptured and its ventral margin is weakly concave. The medial surface of both the quadratojugal and the jugal is obscured by the mandibular fragment. The mandibular fragment represents a posterior part of the right mandibular ramus, preserved in its total height, consisting of surangular and angular. The suture between angular and surangular is obscured by the overlying jugal. The lateral surface of the mandibular ramus is strongly sculptured by close-standing, circular pits. In medial view, the ventral margin of the mandibular ramus, representing the angular, is trough-like indented. The preserved medial angular surface is smooth. Dorsally, the medial surface of the surangular is thickened, and also smooth. The lateral wall of the mandibular ramus is much thinner than its ventral and dorsal margins.

$S G P 2001 / 35.4$. The left quadrate (Fig. 1F) is preserved separately. It is incomplete because of the missing anterior tip, but its morphology is identical to that of the right quadrate described above. At the laterodorsal part of the dorsal surface, there is a longitudinally oval and strongly rugose area that represents the contact surface to the quadratojugal.

$S G P$ 2001/35.5. The basioccipital (Fig. 1G) is preserved in connection with the medial parts of both exoccipitals. The basioccipital forms most of the occipital condyle, which is $12 \mathrm{~mm}$ wide in the specimen. In posterior view, the occipital condyle is nearly semi-circular with a ventrally concave margin. The condyle bears a median groove that continues over the condylar surface anteriorly to widen into the bottom of the medullar canal. The left and right dorsolateral fifth of the condyle are formed by the exoccipital and the suture between the latter and the basioccipital is a distinct, simple sutural line. Therefore, the medial walls of the exoccipitals form the lateral walls of the foramen magnum and medullar canal. The sutures between the exoccipitals and the basioccipital continue from the occipital condyle ventrally and diverge slightly, as the basioccipital slightly broadens ventrally to the condyle. On the left exoccipital-basioccipital suture, a foramen is preserved ventrolaterally to the condyle, representing probably the posterior carotid foramen. The occipital surface of the basioccipital is placed smooth ventrally to the occipital condyle. A part of the left basioccipital tuber is preserved ventrally, but only as rather weak structure.

SGP 2001/35.6. This is a bone fragment that represents the dorsal rim of the foramen magnum and the roof of the medullary canal, formed by the exoccipitals. No sutures between the exoccipitals and no significant anatomical details are visible (Fig. 1H). The dorsal rim of the foramen magnum is roughly semicircular.

SGP 2001/35.7. The caudolateral flange of the right pterygoid is preserved separately (Fig. 1I). All margins, except the lateral one, are destroyed and incomplete. The lateral margin is thickened, rugose, and slightly wavy. It represents an articular surface, which in its anterior half contacts the ectopterygoid and in its posterior half is usually covered by cartilage. The dorsal surface of the pterygoid process is tilted in its rostral 

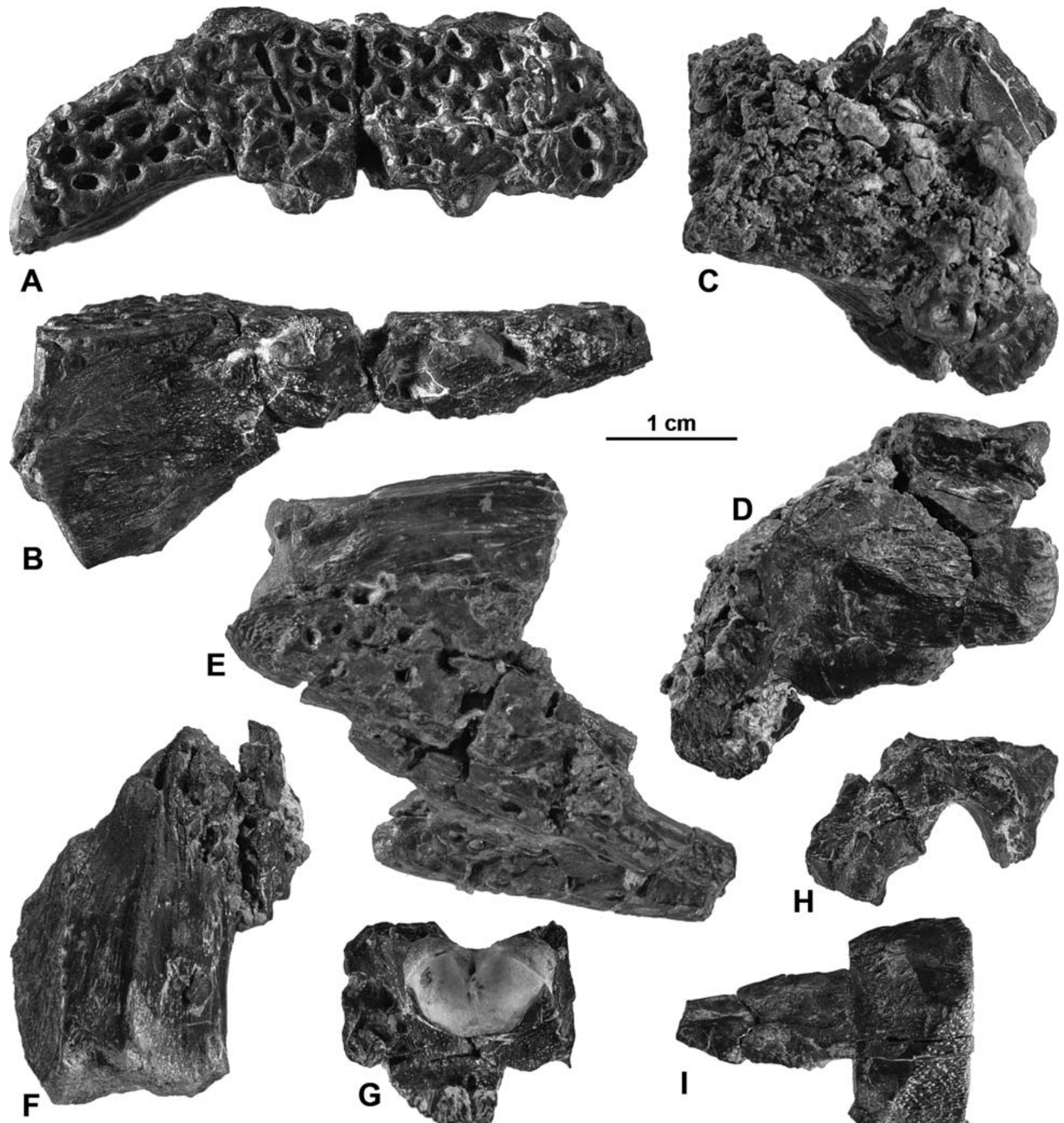

B

$\mathbf{F}$
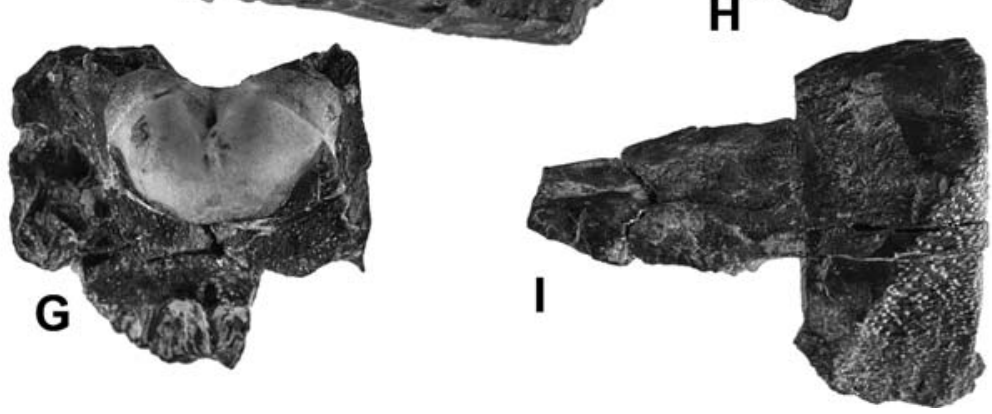

Figure 1. A-B. Skull fragments of Sunosuchus sp. from the Late Jurassic Qigu Formation. Skull roof (SGP 2001/35.1) with parietal and squamosals plus parts of the right supraoccipital, exoccipital, and basioccipital in dorsal (A) and posterior view (B); CD. Skull remain with right squamosal and exoccipital plus part of the right quadrate (SGP 2001/35.2) in dorsal (C) and posterior view (D); E. Right quadrate, quadratojugal, jugal and angular (SGP 2001/35.3) in dorsolateral view; F. Left quadrate (SGP 2001/ 35.4) in dorsal view; G. Basioccipital with occipital condyle plus the small medial parts of the exoccipitals (SGP 2001/35.5) in posterior view; H. Dorsal wall of foramen magnum with roof of medullary canal (SGP 2001/35.6); I. Caudolateral process of the right pterygoid (SGP 2001/35.7) in ventral view.

half. The ventral surface is relatively smooth and bears, parallel to the lateral margin, a triangular and weakly rugose sutural area for the ectopterygoid.

SGP 2001/35.8. The posterior end of the right mandible with the mandibular articulation and the retroarticular process (Fig. 2A-F) is well-preserved. Articular and angular can be identified as separate bones on the basis of a simple suture. The angular forms the lateral part of the mandibular part and the base of the retroarticular process. It is laterally heavily sculptured, except the part forming the ventral base of the retroarticular process. The dorsally positioned glenoid fossa is formed by the articular which is medially attached to the angular and forms nearly the whole retroarticular 
process. The retroarticular process is situated on the posteroventral end of the mandible, very low and twice as long as the glenoid fossa. The ventral mandibular margin is straight. The glenoid fossa is $13.5 \mathrm{~mm}$ long, on average $6 \mathrm{~mm}$ wide and elongated in anteromedialposterolateral direction. The fossa is divided by a low median transverse crest into a narrow medial and a wide lateral part corresponding and fitting to the quadrate hemicondyles. Posteriorly to the broad glenoid surface, the retroarticular process is strongly ventrally sloping and extends with its long axis in mediodorsallateroventral direction. The ventral surface of the retroarticular process is broadened and medially directed. The dorsal face of the retroarticular process is slightly concave and tapers in posterior direction, but it is gen- erally expanded. The dorsal articular surface might have been overlapped by the surangular. The preserved dorsal margin slopes ventrally anterior to the glenoid surface. In medial view, the glenoid fossa overhangs the medial articular wall. The articular is medially smooth and slightly concave. The ventral part of the angular is smooth and separated from the dorsally following articular by a step.

$S G P 2001 / 35$.9. It is the anteriormost fragment of the right angular bone (Fig. $2 \mathrm{G}$ ) with a strongly sculptured lateral side. The sculpture consists of regular and closestanding circular pits very similar to those of the posterior part of the mandible. Medially, the posteriormost fragment of the right splenial is preserved attached to the angular. The medial bone of the angular fragment
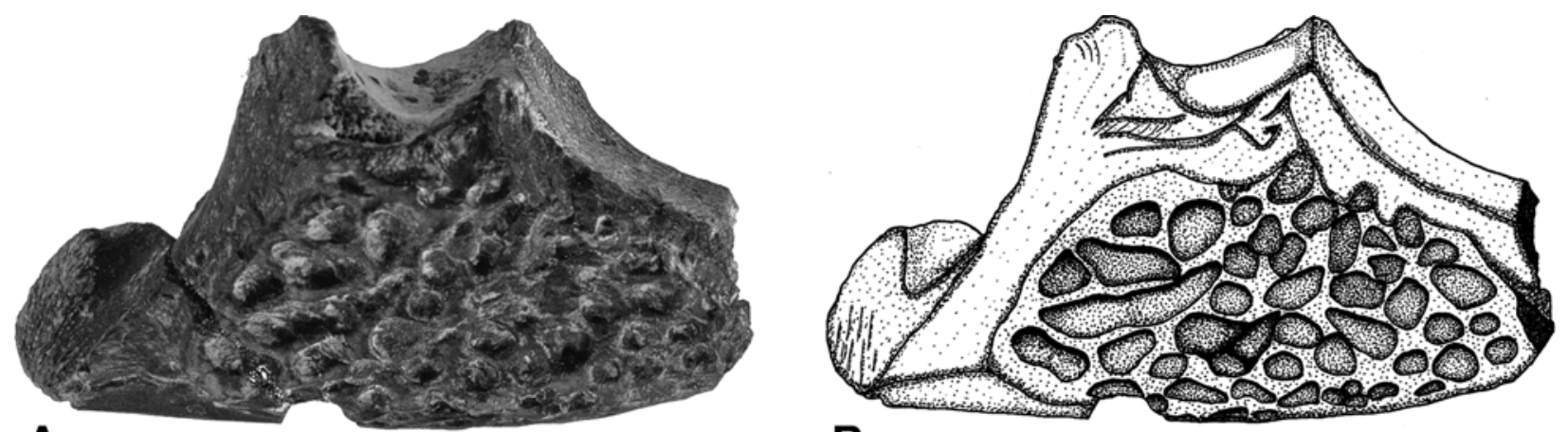

A
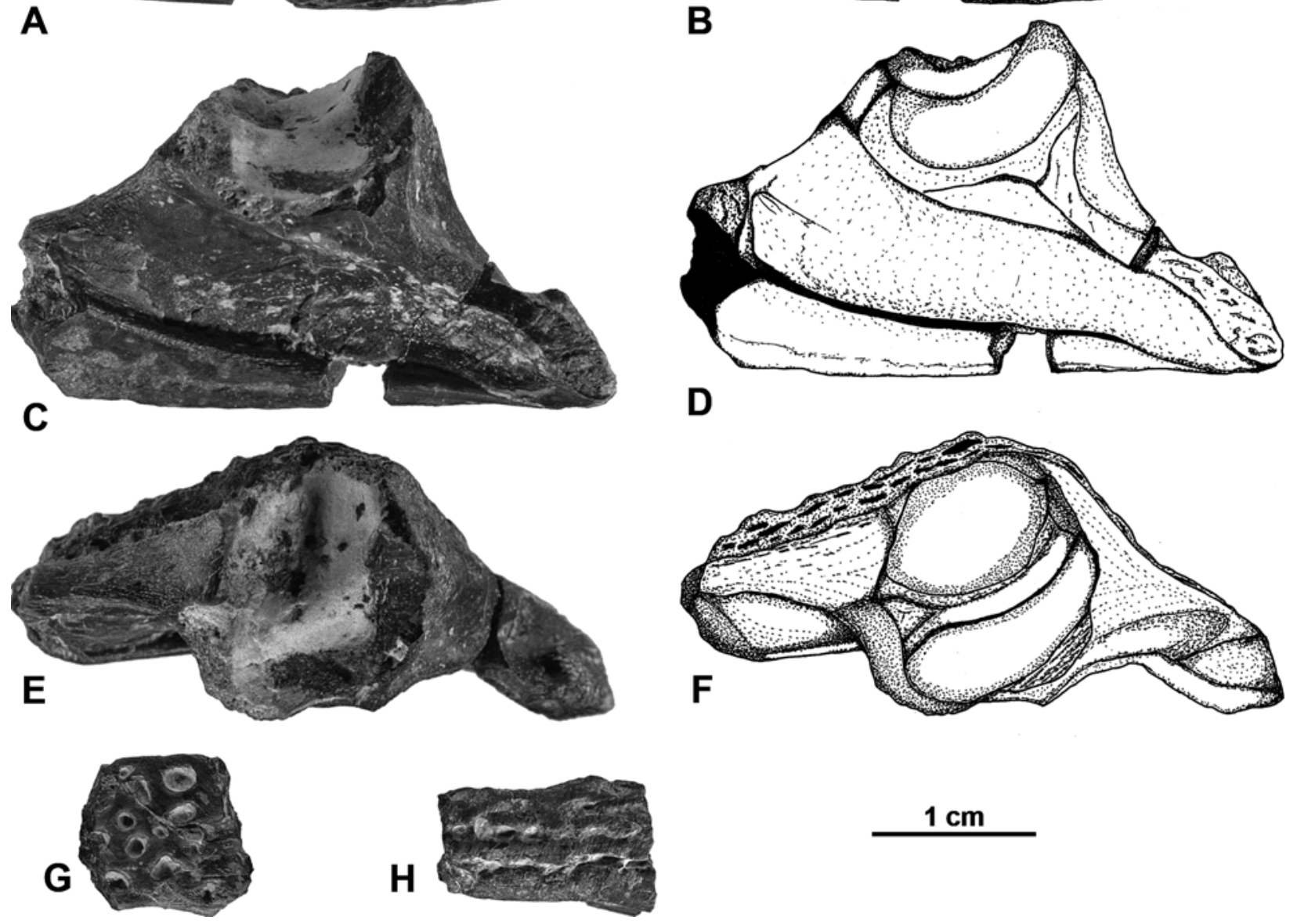

$1 \mathrm{~cm}$

Figure 2. Mandibular fragments of Sunosuchus sp. from the Late Jurassic Qigu Formation. A-F. Posterior end of the right mandible (SGP 2001/35.8); photographs (A, C, E) and line drawings (B, D, F); lateral (A, B), medial (C, D), and dorsal views (E, F). G. Right angular fragment (SGP 2001/35.9) in lateral view; H. Right dentary fragment (SGP 2001/35.10) in lateral view. 
forms a dorsally open trough, the posterior floor of the Meckelian canal, to which the splenial does not contribute.

SGP 2001/35.10. It is a small piece of a right dentary (Fig. $2 \mathrm{H}$ ), presumably from the same mandibular ramus as the other bones. The fragment is laterally sculptured with small pits lying in longitudinal grooves. Medially, it forms a dorsally open trough that constitutes the floor of the Meckelian canal. There is no trace of the splenial, which seems to have been attached farther dorsally to the dentary. In ventral view, the dentary fragment bears a longitudinally oval depression.
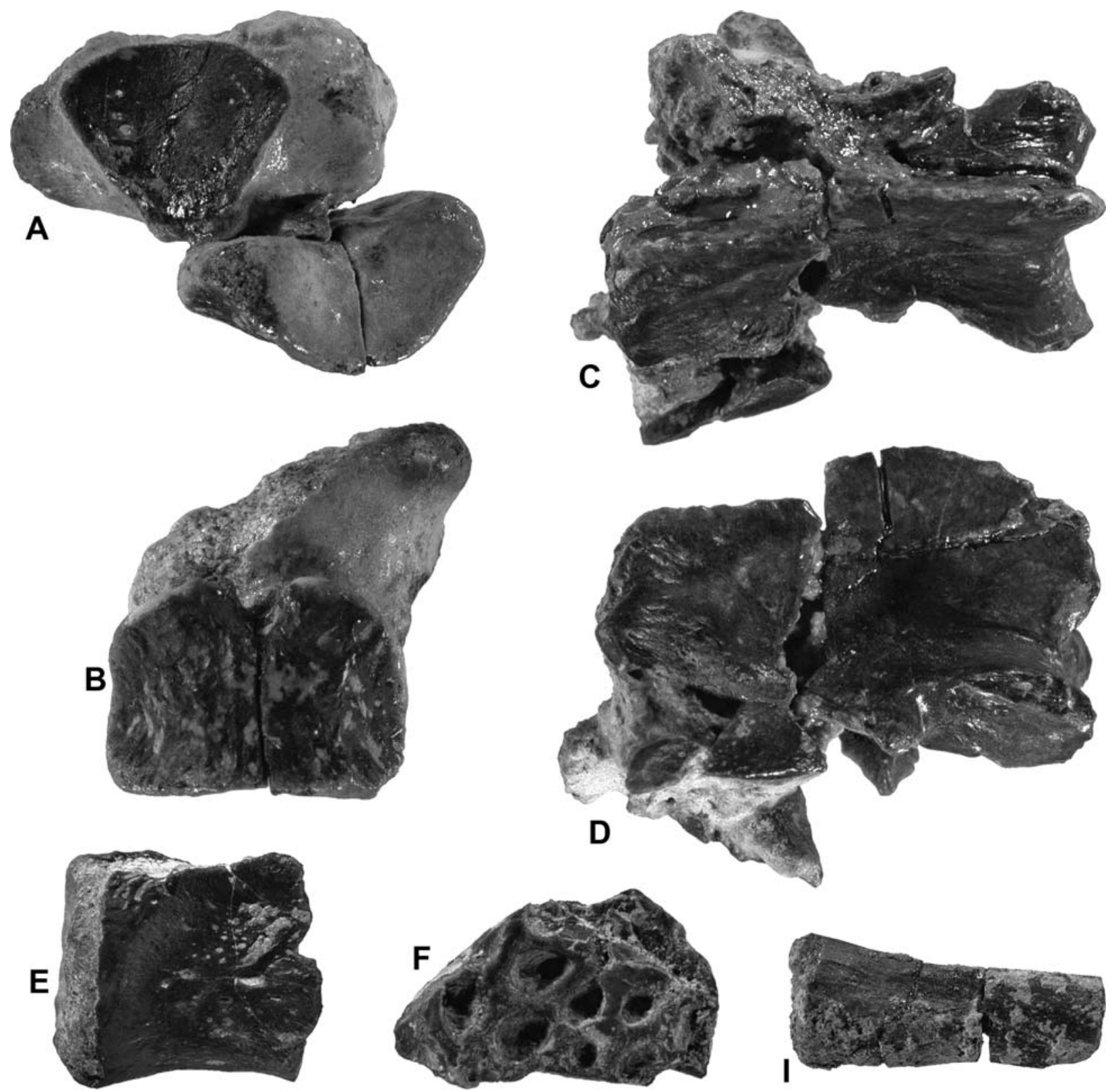

D
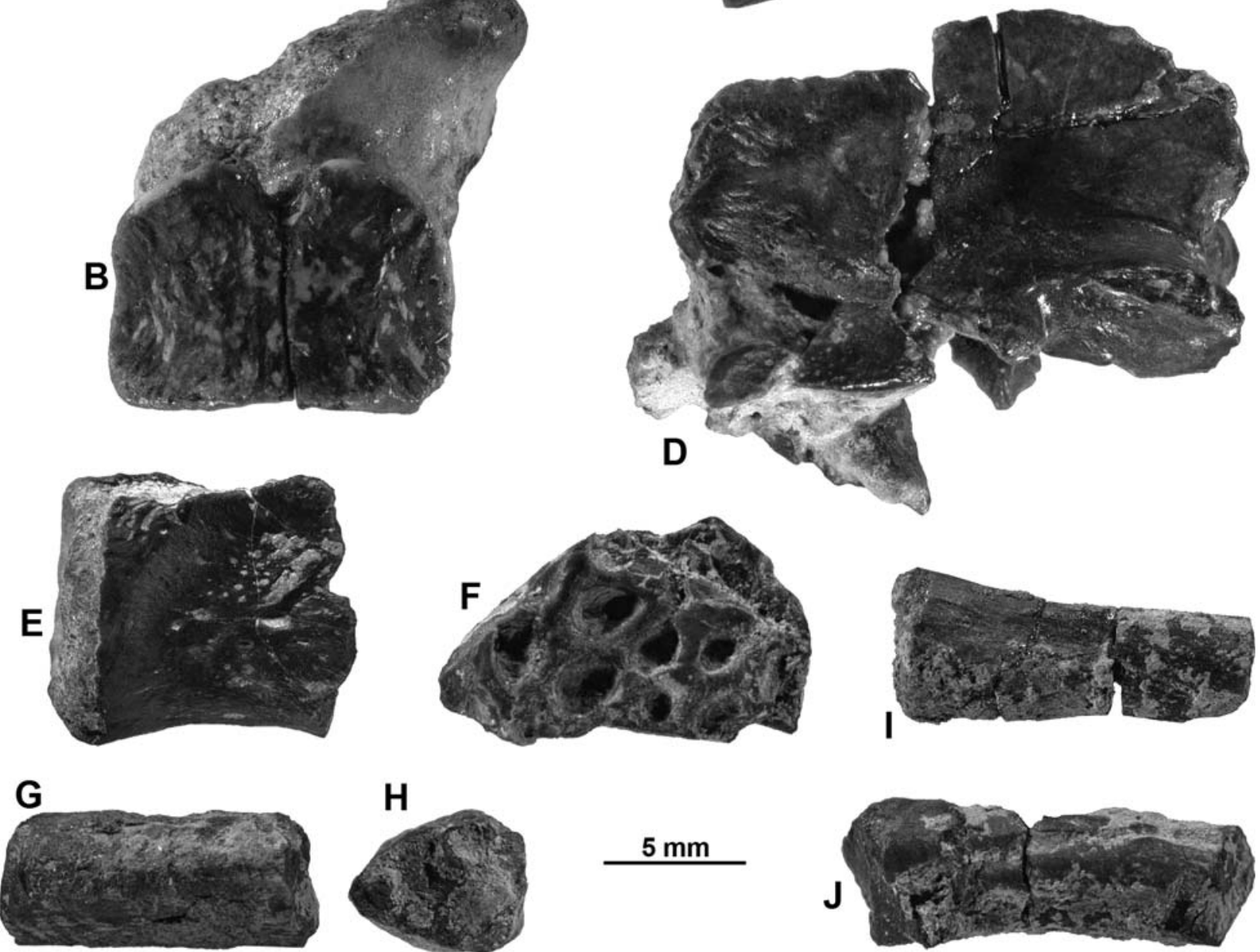

$5 \mathrm{~mm}$

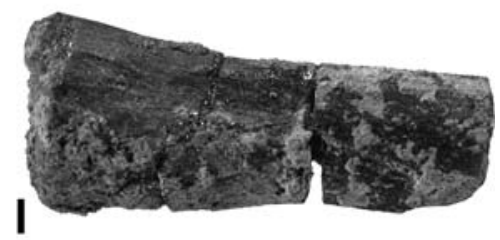

Figure 3. Postcranial elements of Sunosuchus sp. from the Late Jurassic Qigu Formation. A. Atlas intercentrum and odontoid (SGP 2001/35.11), atlas in anterior view in anatomical position, whereas odontoid is turned upside down, but also in anterior view; B. Ventral view of atlas intercentrum with left half of odontoid exposed; C-D. Neural arch of axis (SGP 2001/35.12) in dorsal (C) and lateral view (D); E. Fragmentary vertebral body of ?axis (SGP 2001/35.13) in lateral view; F. Preserved osteoderm fragment (SGP 2001/35.15) in external view; G-H. Rib fragment (SGP 2001/35.14) in G. lateral view (G) and cross-section (H); I. Metacarpal fragment (SGP 2001/35.16) in dorsal view; J. Possible part of an ulna (SGP 2001/35.17) in lateral view. 
SGP 2001/35.11. This is an atlas intercentrum preserved as attached to the odontoid process, but not in anatomical relationships. The intercentrum of the atlas (Fig. 3A, B) is broken in the middle. The intercentrum is twice as broad as it is long and wedge-shaped in lateral view. The dorsal side is slightly concave. The ventral surface of the intercentrum is convex and laterally slightly indented. The anterior occipital articular surface is kidney-shaped with a convex ventral and a concave dorsal side, and transversely curved. The posterior margin of the atlas intercentrum bears a distinct median indentation with a depth of 1-2 mm. The odontoid process is approximately twice as large as the intercentrum, and also wedge-shaped in lateral view. Its anterior occipital articular surface is trapezoidal in outline, with the lateral margins diverging in ventral direction. The occipital articular surface is bowl-shaped impressed. Laterodorsally, a left and a right plane articular surface for the atlantal arches is exposed. The dorsal surface of the odontoid process is smooth and weakly convex, the ventral surface is plane and rugose. Posteriorly, the odontoid process is twice as broad as it is long and strongly rugose to articulate with the vertebral body of the axis.
SGP 2001/35.12. The neural arch of the axis (Fig. 3C, D) is preserved separately. The length of the neural arch indicates a minimal length of $20 \mathrm{~mm}$ for the axis. The neural spine of the axis is thin and bladelike and extends over the whole length of the neural arch. Its dorsal margin is convex and slightly rugose. The neural spine increases in height in posterior direction to reach directly anteriorly to the postzygapophyses a maximum height of $8 \mathrm{~mm}$. The articulation surface of the postzygapophyses is nearly circular with a diameter of 5-6 $\mathrm{mm}$. The angle between the articulation surface and a horizontal line is about $50^{\circ}$.

SGP 2001/35.13. The single preserved vertebral centrum is incomplete but by its size and stratigraphical provenance it might be attributed to same specimen that yielded the axis (Fig. 3E). No distinctive features are preserved that would allow exact identification, so that this vertebra can only be considered to be a presacral vertebra. The bone consists of half of a vertebral centrum with one articular end preserved. The preserved articular surface bears a bowl-like impression surrounded by a rim. The articular surface has a height of $7 \mathrm{~mm}$ and a breadth of $8 \mathrm{~mm}$. The lateral sides of the centrum con-

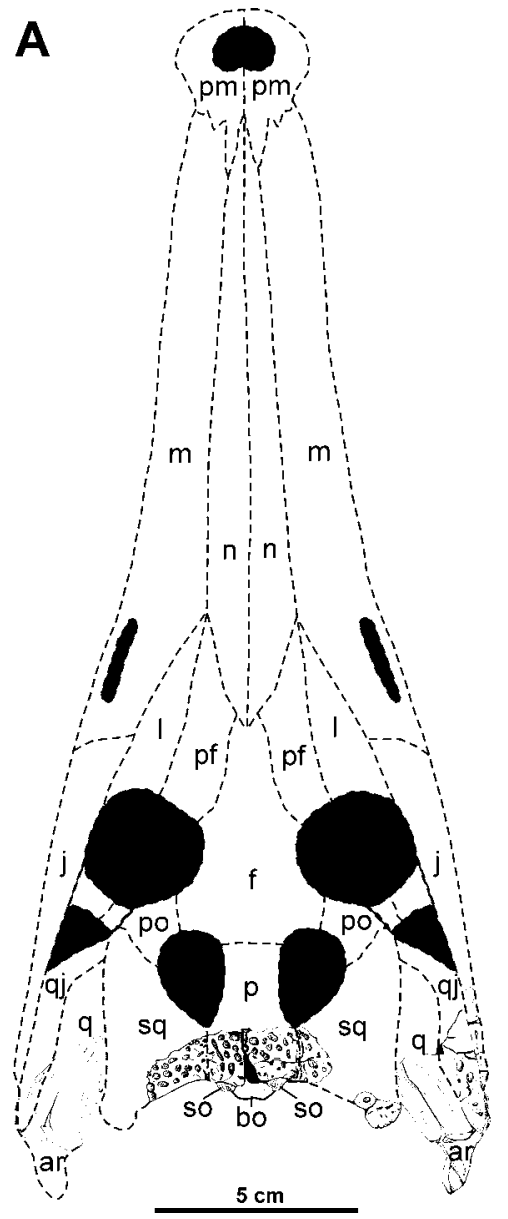

B
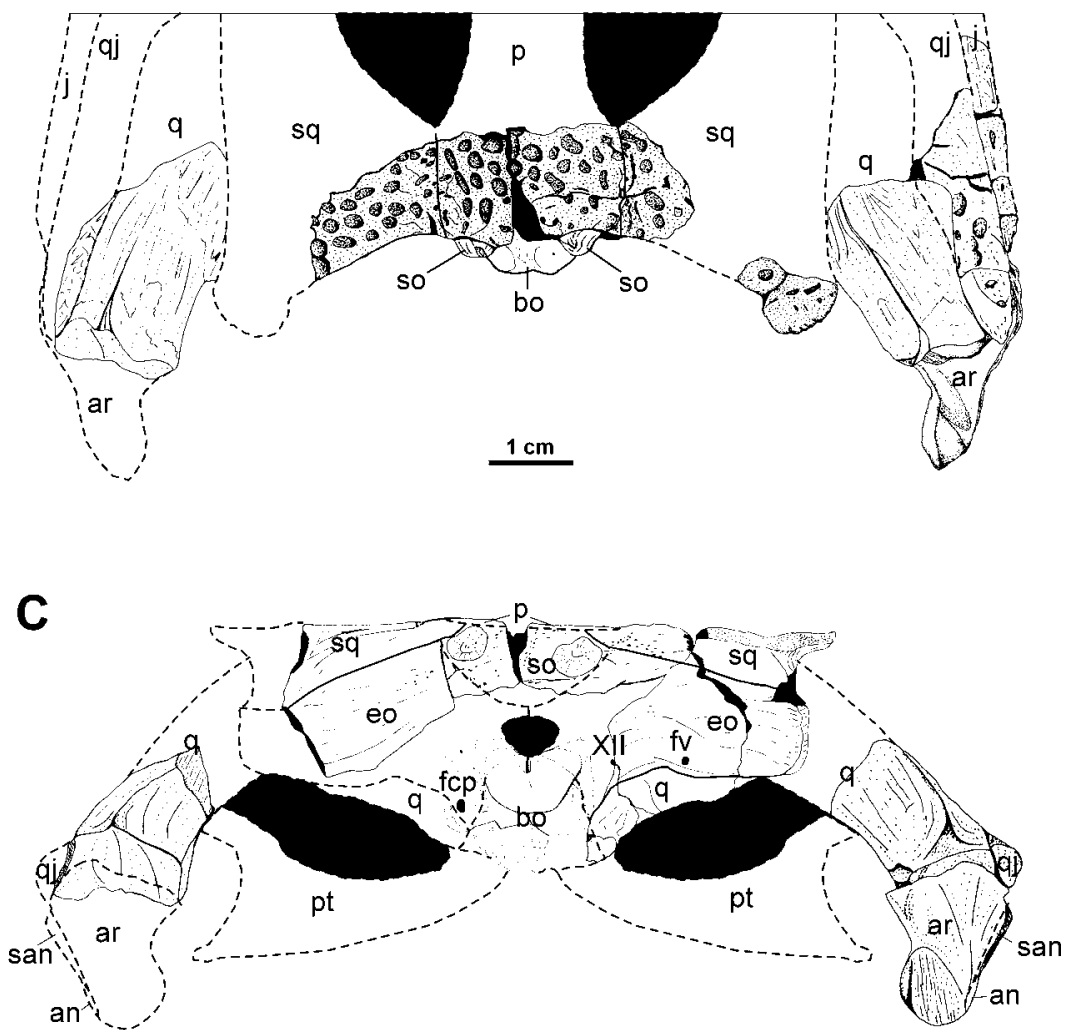

Figure 4. Reconstruction of the skull of Sunosuchus sp. from the Late Jurassic Qigu Formation. A. Dorsal view, anterior outline of skull taken from drawing of S. junggarensis (Wu et al. 1996); B. Occipital region in detail; C. Posterior view. Abbreviations: an angular; ar - articular; bo - basioccipital; eo - exoccipital; f - frontal; fcp - foramen caroticum posterius; fv - foramen vagi; j - jugal; $\mathbf{l}$ - lacrimal; m - maxilla; $\mathbf{n}$ - nasal; p - parietal; pf - prefrontal; pm - premaxilla; po - postorbital; pt - pterygoid; $\mathbf{q}$ - quadrate; qj - quadratojugal; san - surangular; so - supraoccipital; sq - squamosal; XII - foramen XIIth cranial nerve. 
verge in ventral direction, so that the ventral part of the vertebra is narrow. Dorsally, the floor of the neural canal and the laterally adjacent, jagged neurocentral sutures for the insertion of the neural arch are visible.

SGP 2001/35.15. A small osteoderm fragment (Fig. 3F) is preserved. It is $13 \mathrm{~mm}$ long, $8 \mathrm{~mm}$ wide and at least $3 \mathrm{~mm}$ thick. Its external surface bears deep and rounded nearly circular pits. The internal surface is smooth. Additionally, there is a rib fragment (Fig. 3G, H; SGP 2001/35.14) preserved without proximal and distal ends. It is nearly $11 \mathrm{~mm}$ long, $6 \mathrm{~mm}$ in height and $4.5 \mathrm{~mm}$ wide, and has a triangular cross-section. The proximal end of a metacarpal (Fig. 3I; SGP 2001/35.16) is also preserved. The fragment is nearly $13 \mathrm{~mm}$ long. The fragment is ventrally flat and dorsally slightly convex. The proximal end is one-third wider than the shaft. The proximal articular surface is nearly flat and about $5.5 \mathrm{~mm}$ wide and $3 \mathrm{~mm}$ high. Another preserved long bone fragment may represent a part of an ulna (Fig. 3J; SGP 2001/35.17) without articular ends, and with a slightly curved shaft. The cross-section of the shaft is more or less circular and the fragment is $15 \mathrm{~mm}$ long, and up to $6 \mathrm{~mm}$ in diameter.

\section{Ontogenetic status of the specimen}

In extant crocodylians, a distinct caudal-to-cranial sequence is observed for the closing of the neurocentral suture (Brochu 1996). Closed neurocentral sutures in cervical vertebrae indicate a high maturity index. The neurocentral suture of the axis is closed only in large and old individuals. The odontoid-axis suture closes earlier than the axial neurocentral suture (Brochu 1996). In the described bone material, the axial neurocentral suture and the odontoid-axis suture are fully open. The lack of a more posterior cervical vertebra allows no interpretation of maturity other than that it was not an aged specimen.

Total skull lengths of $23.5 \mathrm{~cm}, 26.5 \mathrm{~cm}$, and $41-$ $42 \mathrm{~cm}$ are reported from Sunosuchus junggarensis ( $\mathrm{Wu}$ et al. 1996). The large specimen probably represents a very old or, at least, one of the largest individuals of $S$. junggarensis. Even the small specimens are considered to be adult, because of the absence of the frontal suture on the dorsal surface, the position of the anterior foramen for the temporoorbital artery, and the presence of a short alveolar groove for the posteriormost maxillary teeth (Wu et al. 1996). Because of the fragmentary preservation of the described skull, these criteria can not be compared. But with an estimated skull length of not much less than $30 \mathrm{~cm}$, the present specimen is considered to be at least subadult.

\section{Discussion}

Wu et al. (1996) revised the diagnosis of Young (1948) and defined the following derived characters for the medium-sized mesoeucrocodylian genus Sunosuchus,
(1) a narrow rostral skull, which is more than twice as long as the postorbital region, (2) a small skull table less than $60 \%$ of width of skull along a line across supratemporal fenestrae; (3) frontal with a ridge along midline; (4) expanded dorsal surface of retroarticular process facing lateroventrally-mediodorsally, (5) large pits wider than long on posterior surface of frontal, (6) symphysis of dentaries elongated and with a short contribution from splenial. Wu et al. (1996) listed also “(4) palatal fenestrae located well anterior to suborbital fenestrae" as diagnostic character of Sunosuchus, however, this character is shared with all North-American goniopholidids (Salisbury et al. 1999), i.e. Eutretauranosuchus (as remarked by Wu et al. 1996) and Goniopholis stovalli Mook, 1964, G. lucasii (Cope, 1878) (Mook 1942), G. gilmorei Holland, 1905, and G. felix (Marsh, 1877). Other goniopholidid characters present in Sunosuchus are an elongated mandibular symphysis (shared with Eutretauranosuchus and Vectisuchus), maxillary depressions, elongated narrow choanae partly extending behind suborbital fenestrae, and a strongly developed crest B on ventral surface of quadrate (shared with Goniopholis and Eutretauranosuchus (Wu et al. 1996)). In SGP 2001/35, only character (4), a short and ventrally sloping, expanded retroarticular process, and the posteriorly straight skull roof with characteristically lobe-like and unsculptured posterolateral process of the squamosal allow assignment to Sunosuchus. In fact, SGP 2001/35 resembles the holotype of Sunosuchus miaoi (Buffetaut 1986, fig. 1), Sunosuchus sp. from Kyrgyzstan (Averianov 2000, fig. 1b), S. shartegensis (Efimov 1988a, 1988b), and S. junggarensis (Wu et al. 1996, fig. 6d) in having such a tongue-like and unsculptured posterolateral process of the squamosal. Hence, we consider this squamosal configuration to be characteristic on the generic level, and incorporate it into the genus diagnosis. The strongly developed crest B of the quadrate described for SGP 2001/35 is found in most goniopholidids and further supports the assignment of the specimen to this crocodylian group.

The species comparison is difficult because of the frequently missing overlap between the individuals assigned to Sunosuchus. The type species S. miaoi (Young 1948) is represented by a mostly complete posterior part of the skull with the complete left mandibular ramus, and some postcranial elements like vertebrae, cervical ribs, and a few osteoderms. S. junggarensis (Wu et al. 1996) is represented by six individuals including cranial and postcranial elements. It is the best described species of Sunosuchus and possesses the most overlap in preserved bone material to the specimen here described. The description and drawings of $S$. shartegensis (Efimov 1988a, 1988b) are based on an almost complete skull with a fragment of the right lower jaw, but are unfortunately insufficient. S. thailandicus (Buffetaut \& Ingavat $1980,1984)$ was described from a nearly complete preserved lower jaw. Cranial and postcranial elements of Sunosuchus sp. described from Kyrgyzstan (Averianov 2000) and the southern Junggar Basin (Maisch et al. 2003b) are only partially comparable. 
A comparison with other published taxa of Sunosuchus reveals differences of SGP 2001/35. The latter differs from S. shunanensis (Fu et al. 2005) by the presence of a ridge dividing the dorsally arched quadrate and the absence of a "flange" at the basioccipital-exoccipital suture ventrally to the occipital condyle. SGP 2001/35 differs from S. thailandicus (Buffetaut \& Ingavat 1980, 1984) and S. miaoi (Buffetaut 1986; Young 1948) by its retroarticular process, which is in the latter two much broader and not as strongly ventrally directed. Furthermore, the dorsal mandibular margin of S. miaoi and Sunosuchus from the Toutunhe Formation (Maisch et al. 2003b) is anterior to the glenoid as high as the latter, whereas it slopes ventrally in SGP $2001 / 35$.

SGP 2001/35 shows many similarities to Sunosuchus junggarensis as described by $\mathrm{Wu}$ et al. (1996), which is not only an effect of the large overlap in the preserved bones. Similarities are the parietals with an almost straight posterior margin and visible, straight parietalsquamosal sutures, squamosals with a lobe-like and unsculptured posterolateral process, the narrow, straight and elongated posterior process of the jugal, the anterodorsally unsculptured dorsal surface of the quadratojugal, the dorsally arched quadrate divided by a ridge in a dorsolateral and a dorsomedial portion, a deep ventral depression adjacent to the strongly developed crest B of the quadrate, presence of a crest $A$ of the quadrate with a shallow depression between crest $\mathrm{A}$ and crest $\mathrm{B}$, a massive pterygoid flange with a thickened lateral margin, an exoccipital with the foramen for the cranial nerve XII being medially displaced from the foramen for the cranial nerves IX-XI, a small and dorsoventrally narrow supraoccipital with a pair of depressions on the occipital face, a mandibular articular fossa divided by a median ridge into a larger lateral and a smaller medial portion, a medially directed and broad ventral surface of the retroarticular process, a ventrally sloping mandibular margin anterior to the glenoid, a similar intercentrum of the atlas with a medial incision on its posterior end, and a low and blade-like neural spine of the axis. However, SGP 2001/35 differs from $S$.junggarensis in having a large occipital squamosal extension, a shorter and higher quadratojugal articular face on the quadrate, two distinct supraoccipital processes and a median ridge on the supraoccipital dividing the supraoccipital depressions. This makes an assignment of the described specimen to S.junggarensis unlikely.

The differences between SGP 2001/35 and all of the species of Sunosuchus allow the possibility that the bones belong to a new taxon of Sunosuchus. Despite missing overlap between these taxa, significant differences concerning the configuration of the posterior mandible (i.e., retroarticular process and glenoid region in comparison with $S$. miaoi and S. thailandicus), and the skull (occipital and quadrate regions in S. junggarensis and S. shunanensis) do exist. However, the insufficient description of $S$. shartegensis makes this taxon possibly a nomen dubium (see also discussion in Maisch 2003b). This prohibits a differential diagnosis to $S$. shartegensis, also because we were unable to study the S. shartegensis material. The possibility that SGP 2001/35 might represent an already described taxon can therefore not be ruled out. Consequently, assignment of SGP 2001/35 is only made at generic level.

\section{Stratigraphical and geographical occurrence of Sunosuchus and other goniopholidids}

Buffetaut \& Ingavat $(1980,1984)$ described a lower jaw of the species S. thailandicus from the Phu Kradung Formation of the Khorat Group of NE Thailand (Fig. 5). This formation is dated as probably Early Jurassic and represents therefore the geologically oldest record of Sunosuchus. Middle Jurassic (Callovian) finds of Sunosuchus sp. are known from Balabansai Svita in Kyrgyzstan with skull fragments and postcranial elements (Averianov 2000) and from the Toutunhe Formation near Liuhuanggou in the southern Junggar Basin (Maisch et al. 2003b). Another Chinese Middle Jurassic species, S. shunanensis, was described recently from the Xiashaximiao Formation in Dashanpu, Zigong, Sichuan province (Fu et al. 2005).

S. junggarensis, the best known and described taxon, was found in the Late Jurassic Shishugou Formation of Pingfengshan (Wucaiwan) in the Junggar Basin of NW China (Wu et al. 1996). The exact stratigraphic occurrence of $S$. junggarensis is not mentioned in the original description, but it can be interpreted to be Oxfordian in age (Maisch et al. 2003b).

The type species of Sunosuchus, S. miaoi (Young 1948), is described from Late Jurassic sediments of the Chinese province Gansu (Young 1948), however, Buffetaut (1986) determined the sediments to be of Early Cretaceous age. S. shartegensis from the Late Jurassic (Efimov 1988a, 1988b) or Early Cretaceous (Wu et al. 1996) deposits of SW Mongolia is another Sunosuchus taxon.

Including the new finding, the taxon Sunosuchus occurred during an exceptionally long time range of about 60 million years, ranging from Early Jurassic to possibly Early Cretaceous strata. This holds even if uncertainties in dating the respective formations are taken into account. However, it is well in accordance with long time ranges for the closely related taxon Goniopholis, which is present in Europe from Middle Jurassic (Bathonian) to Early Cretaceous (Abtian) strata. Geographically, Sunosuchus is currently restricted to Asia, with possible overlap with Goniopholis phuwiangesis (Buffetaut \& Ingavat 1983) and the goniopholidid Siamosuchus phuphokensis (Lauprasert et al. 2007) in Thailand. The geographical restriction is also evident in other members of Goniopholididae and might correspond to existing geographical barriers, such as the opening North Atlantic between North America and Europe and the Tethyan ocean between the European 


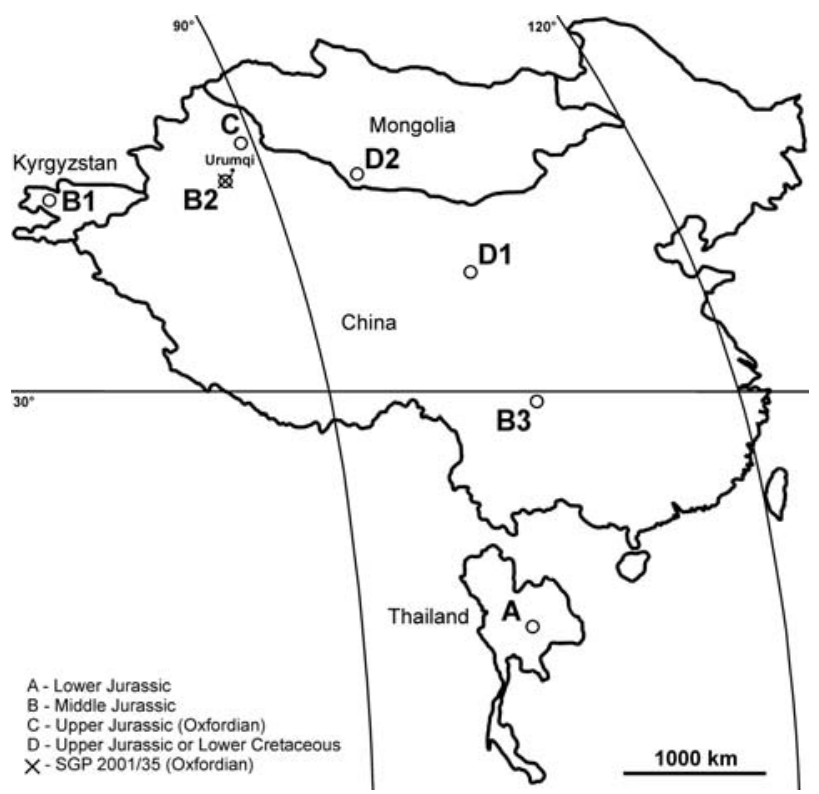

Figure 5. Schematic map of China, Kyrgyzstan, Mongolia, and Thailand showing localities of Sunosuchus and their geological age. A. Amphoe Nong Bua Lam Phu (NE Thailand), Early Jurassic Phu Kradung Formation, S. thailandicus (Buffetaut \& Ingavat 1980, 1984); B1. Sarykamyshsai 1 (Osh province, Kyrgyzstan), Middle Jurassic (Callovian) Balabansai Svita, Sunosuchus sp. (Averianov 2000); B2. Liuhuanggou (Xinjiang province, NW China), Middle Jurassic (Callovian) Toutunhe Formation, Sunosuchus sp. (Maisch et al. 2003b); B3. Dashanpu (Sichuan province, China), Middle Jurassic Xiashaximiao Formation, S. shunanensis (Fu et al. 2005); C. Pingfengshan (Xinjiang province, NW China), Late Jurassic Shishugou Formation, S. junggarensis (Wu et al. 1996); D1. Hanchiahukou (Gansu province, China), Late Jurassic or Early Cretaceous Hokou Series, S. miaoi (Young 1948); D2. Shar Teg (SW Mongolia), Late Jurassic or Early Cretaceous, S. shartegensis (Efimov 1988a, 1988b); x. Liuhuanggou (Xinjiang province, NW China), Late Jurassic (Oxfordian) Qigu Formation, Sunosuchus sp. SGP 2001/35, the specimen described in this paper.

archipelago and the Asian land mass during the Jurassic and Cretaceous, which led to a separation of a North American group of goniopholidids that possibly all belong to Eutretauranosuchus (Salisbury et al. 1999), the European Goniopholis, and the Asian Sunosuchus discussed herein.

\section{Acknowledgements}

We sincerely thank the staff of the Geological Survey No 1 of Xinjiang and the members of the Sino-German Project for logistic support and assistance in the field during collection of the specimen. All photographs were taken by Wolfgang Gerber (Tübingen). We gratefully acknowledge the financial support of the field work by the Natural Science Foundation and Academia Sinica of China, the Deutsche Forschungsgemeinschaft (DFG), and the Max-Planck-Gesellschaft of Germany. Current funding is provided for RS by the Landesgraduiertenförderung Baden-Württemberg and for OW by the DFG (PF 219/ 21). We are grateful to the two referees Massimo Delfino and Attila Ösi for their constructive comments and suggestions on the manuscript.

\section{References}

Averianov, A. O. 2000. Sunosuchus sp. (Crocodylomorpha, Goniopholididae) from the Middle Jurassic of Kirghisia. - Journal of Vertebrate Paleontology 20 (4): 776-779.

Benton, M. J. \& Clark, J. M. 1988. Archosaur phylogeny and the relationships of the Crocodilia. In Benton, M. J. (ed.). The phylogeny and classification of tetrapods. Vol. 1: Amphibians and Reptiles. Volume Systematics Associations Special Volume No. 35A. Clarendon Press, Oxford: pp. 295-338.

Brochu, C. A. 1996. Closure of neurocentral sutures during crocodilian ontogeny: implications for maturity assessment in fossil archosaurs. - Journal of Vertebrate Paleontology 16 (1): 49-62.

Buffetaut, E. 1986. Remarks on the anatomy and systematic position of Sunosuchus miaoi Young, 1948, a mesosuchian crocodilian from the Mesozoic of Gansu, China. - Neues Jahrbuch für Geologie und Paläontologie, Monatshefte 1986 (11): 641-647.

Buffetaut, E. \& Ingavat, R. 1980. A new crocodilian from the Jurassic of Thailand, Sunosuchus thailandicus n. sp. (Mesosuchia, Goniopholididae), and the palaeogeographical history of South-East Asia in the Mesozoic. - Geobios 13 (6): 879-889.

Buffetaut, E. \& Ingavat, R. 1983. Goniopholis phuwiangensis nov. sp., a new mesosuchian crocodile from the Mesozoic of North-Eastern Thailand. - Geobios 16 (1): 79-91.

Buffetaut, E. \& Ingavat, R. 1984. The lower jaw of Sunosuchus thailandicus, a mesosuchian crocodilian from the Jurassic of Thailand. - Palaeontology 27 (1): 199-206.

Clark, J. M. 1986. Phylogenetic relationships of the crocodylomorph archosaurs. Ph.D. dissertation, University of Chicago, Chicago, Illinois: $551 \mathrm{p}$.

Cope, E. D. 1875. Check-list of North American Batrachia and Reptilia. - Bulletin of the U.S. National Museum 1: 1-109.

Cope, E. D. 1878. Descriptions of new extinct Vertebrata from the Upper Tertiary and Dakota Formations. - Bulletin of the United States Geological and Geographical Survey of the Territories 4 (2): 379-396.

Dong Zhiming 1993. An ankylosaur (ornithischian dinosaur) from the Middle Jurassic of the Junggar Basin, China. - Vertebrata PalAsiatica 31: 258-265.

Dong Zhiming 2001. Mesozoic Fossil Vertebrates from the Junggar Basin and Turpan Basin, Xinjiang, China. - Proceedings of the Sino-German Cooperation Symposium on the Prehistory Life and Geology of Junggar Basin, Xinjiang, Urumqi 2001: 95-103.

Efimov, M. B. 1988a. On the fossil crocodiles of Mongolia and the USSR. - Trudy Sovmestnoi Sovetsko-Mongol'skoi Paleontologicheskoi ekspeditsii 34: 81-90 [in Russian].

Efimov, M. B. 1988b. The fossil crocodiles and champsosaurids of Mongolia and the USSR. - Trudy Sovmestnoi Sovetsko-Mongol'skoi Paleontologicheskoi ekspeditsii 36: 1-108 [in Russian].

Fu Qian-Ming, Ming Shu-Ying \& Peng Guang-Zhao 2005. A new species of Sunosuchus from Zigong, Sichuan, China. - Vertebrata PalAsiatica 43 (1): 76-83 [in Chinese with English abstract].

Hay, O. P. 1930. Second Bibliography and Catalog of the Fossil Vertebrata of North America. Volume 2. Carnegie Institute, Washington.

Holland, W. J. 1905. A new Crocodile from the Jurassic of Wyoming. - Annals of the Carnegie Museum 3 (3): 431-434.

Iordansky, N. N. 1973. The skull of the Crocodilia. In Gans, C. (ed.). Biology of the Reptilia.Volume 4. Academic Press, London: pp. 201-262.

Lauprasert, K., Cuny, G., Buffetaut, E., Suteethorn, V. \& Thirakhupt, K. 2007. Siamosuchus phuphokensis, a new goniopholidid from the Early Cretaceous (ante-Aptian) of northeastern Thailand. Bulletin de la Société Géologique de France 178 (3): 201-216.

Maisch, M. W. \& Matzke, A. T. 2005. Temnospondyl amphibians from the Jurassic of the Southern Junggar Basin (NW China). Paläontologische Zeitschrift 79 (2): 285-301. 
Maisch, M. W., Matzke, A. T., Pfretzschner, H.-U., Ye Jie. \& Sun Ge 2001. The fossil vertebrate faunas of the Toutunhe and Qigu Formations of the Southern Junggar Basin and their biostratigraphical and palecological implications. - Proceedings of the Sino-German Cooperation Symposium on the Prehistory Life and Geology of Junggar Basin, Xinjiang, Urumqi 2001: 83-94.

Maisch, M. W., Matzke, A. T., Pfretzschner, H.-U., Sun Ge, Stöhr, H. \& Großmann, F. 2003a. Fossil vertebrates from the Middle and Upper Jurassic of the Southern Junggar Basin (NW China) - results of the Sino-German Expeditions 1999-2000. - Neues Jahrbuch für Geologie und Paläontologie, Monatshefte 2003 (5): 297313.

Maisch, M. W., Matzke, A. T. \& Stöhr, H. 2003b. Sunosuchus (Archosauria, Crocodyliformes) from the Toutunhe Formation (Middle Jurassic) of the Southern Junggar Basin (Xinjiang, NW-China). Geobios 36: 391-400.

Maisch, M. W., Matzke, A. T., Großmann, F., Stöhr, H., Pfretzschner, H.-U. \& Sun Ge 2004. The first haramyoid mammal from Asia. Naturwissenschaften 92 (1): 40-44.

Marsh, O. C. 1877 . Notice of some new vertebrate fossils. - American Journal of Arts and Sciences 14: 249-256.

Matzke, A. T., Maisch, M. W., Sun Ge, Pfretzschner, H.-U. \& Stöhr, H. 2004. A new xinjiangchelyid turtle (Testudines, Eucryptodira) from the Jurassic Qigu Formation of the southern Jungar Basin, Yinjiang, North-West China. - Palaeontology 47 (5): 1267-1299.

Matzke, A. T., Maisch, M. W., Sun Ge, Pfretzschner, H.-U. \& Stöhr, H. 2005. A new Middle Jurassic xinjiangchelyid turtle (Testudines; Eucryptodira) from China (Xinjiang, Junggar Basin. Journal of Vertebrate Paleontology 25 (1): 63-70.

Mook, C. C. 1942. Skull characters of Amphicotylus lucasii Cope. American Museum Novitates 1165: 1-5.

Mook, C. C. 1964. New species of Goniopholis from the Morrison of Oklahoma. - Oklahomal Geologial Notes 24: 283-287.
Pfretzschner, H.-U., Martin, T., Maisch, M. W., Matzke, A. T. \& Sun Ge 2005. A new docodont mammal from the Late Jurassic of the Junggar Basin in Northwest China. - Acta Palaeontologica Polonica 50 (4): 799-808.

Salisbury, S. W., Willis, P. M. A., Peitz, S. \& Sander, P. M. 1999. The crocodilian Goniopholis simus from the Lower Cretaceous of NorthWestern Germany. - Special Papers in Palaeontology 60: 121-148.

Walker, A. D. 1970. A revision of the Jurassic reptile Hallopus victor (Marsh), with remarks on the classification of crocodiles. - Philosophical Transactions of the Royal Society of London, B 257 (816): 323-372.

Whetstone, K. N. \& Whybrow, P. 1983. A cursorial crocodilian from the Triassic of Lesotho (Basutoland), South Africa. - Occasional Papers of the University of Kansas 106: 1-37.

Wings, O., Fowler, D. W., Maisch, M. W., Martin, T., Pfretzschner, H.U. \& Sun Ge 2007a. Dinosaur teeth from the Jurassic Qigu and Shishugou Formations of the Junggar Basin, Xinjiang/China and their palaeobiogeographical implications. In Sun Ge, Mosbrugger, V., Sun Yue-Wu \& Bruch, A. (eds). Proceedings of the International Symposium for Sino-German Cooperation on Geology and Environmental Changes in Northern China; Urumqi/China, September 1-7, 2007, Urumqi: pp. 5-10.

Wings, O., Pfretzschner, H.-U. \& Maisch, M. W. 2007b. The first evidence of a stegosaur (Dinosauria, Ornithischia) from the Jurassic of Xinjiang/China. - Neues Jahrbuch für Geologie und Paläontologie, Abhandlungen 243 (1): 113-118.

Wu Xiao-Chun, Brinkman, D. B. \& Russell, A. P. 1996. Sunosuchus junggarensis sp. nov. (Archosauria; Crocodyliformes) from the Late Jurassic of Xinjiang, People's Republic of China. - Canadian Journal of Earth Sciences 33 (4): 606-630.

Young Chung-Chien 1948. Fossil crocodiles in China, with notes on dinosaurian remains associated with the Kansu crocodiles. - Bulletin of the Geological Society of China 28: 225-288. 